ISSN 0103-9954

\title{
INCÊNDIOS FLORESTAIS NO ENTORNO DE UNIDADES DE CONSERVAÇÃO - ESTUDO DE CASO NA ESTAÇÃO ECOLÓGICA DE ÁGUAS EMENDADAS, DISTRITO FEDERAL
}

\section{FOREST FIRES AROUND UNITS OF CONSERVATION - A CASE STUDY IN ÁGUAS EMENDADAS ECOLOGICAL STATION, DISTRITO FEDERAL}

\author{
Eugênio P. Costa ${ }^{1}$ Nilton C. Fiedler ${ }^{2} \quad$ Marcelo B. Medeiros ${ }^{3} \quad$ Fernando B. Wanderley $^{4}$ \\ RESUMO
}

Esta pesquisa foi desenvolvida com objetivo de analisar aspectos sobre o uso do fogo nas circunvizinhanças urbanas da Estação Ecológica de Águas Emendadas (ESECAE), no Distrito Federal, avaliar as principais ocorrências de incêndios, disponibilidade de máquinas, equipamentos e ferramentas para a brigada de combate e fornecer subsídios para diminuição da incidência de incêndios florestais. A população residente nas áreas urbanas do entorno (num raio de três quilômetros) e os brigadistas da unidade de conservação e da guarnição do Corpo de Bombeiros foram entrevistados. Os resultados mostraram que existem áreas mais propensas à ocorrência de incêndios florestais (margens de rodovias e estradas vicinais $33,4 \%$ ) em conseqüência da sua localização e a interação com o meio urbano, onde o fogo era usado na limpeza de terrenos por $34 \%$ da população. Existe disponibilidade de máquinas, equipamentos e ferramentas para a execução das atividades de prevenção e combate, porém, não existem equipamentos de proteção individual (EPI's) para todos os brigadistas. Para a população urbana, as campanhas educativas devem enfatizar as consequências negativas do uso do fogo e os riscos dos incêndios florestais.

Palavras-chave: fogo em unidades de conservação; uso do fogo; educação ambiental.

\section{ABSTRACT}

This study aimed to analyze aspects of fire use on urban areas around Águas Emendadas Ecological Station (ESECAE), in Distrito Federal, and to evaluate the foremost fire occurrences, equipment availability and tools for combatants and beyond decreasing forest fire incidences. The local population in town region around it (considering three kilometers as ray from the station), fire crew members units of conservation and the garrison body of firemen were interviewed in a representative form. Results had shown that most inclined areas to forest fire occurrence (33.4\% highways edges and secondary roads) had their localization related to urban environment, in which $34 \%$ of residents used fire as land cleanness. Machines availability, tools and equipment for execution of the activities on prevention and combat exist; however, there is not any equipment for individual protection for all fire crew members. As a solution, educative campaigns to emphasize the negative consequences of using fire (as a tool land) and also to alert people for the risks caused by it should be done.

Keywords: fire in units of conservation; use of fire; environment education.

\section{INTRODUÇÃO}

Os incêndios florestais podem ocorrer nos mais variados biomas, unidades de conservação, áreas de preservação, fazendas, margens de estradas, proximidades de aglomerados urbanos, áreas de reflorestamento, dentre outras localidades, acarretando, em muitos casos, diversos prejuízos econômicos, paisagísticos e ecológicos. No Brasil, a maioria dos incêndios é provocada por pessoas.

Por outro lado, o Cerrado brasileiro é um ecossistema propenso à ocorrência do fogo, com uma vegetação que apresenta adaptações estruturais e funcionais que proporcionam certa resistência e resiliência a

1. Engenheiro Florestal, M.Sc., Analista Ambiental, Instituto Brasileiro do Meio Ambiente e dos Recursos Naturais Renováveis (IBAMA), SCEN Trecho 2 - Ed. Sede - Caixa Postal 09870, CEP 70818-900, Brasília (DF). eugenio.costa@ibama.gov.br

2. Engenheiro Florestal, Dr., Professor Associado do Departamento de Engenharia Florestal, Centro de Ciências Agrárias, Universidade Federal do Espírito Santo, Alto Universitário, CEP 29500-000, Alegre (ES). fiedler@pq.cnpq.br

3. Biólogo, Dr., Pesquisador da Empresa Brasileira de Pesquisa Agropecuária, Centro Nacional de Pesquisa de Recursos Genéticos e Biotecnologia (CENARGEN), Av. W5 Norte (final), Caixa Postal 02372, CEP 70770-917, Brasília (DF).medeiros@cenargen.embrapa.br

4. Engenheiro Florestal, Departamento de Engenharia Florestal, Centro de Ciências Agrárias, Universidade Federal do Espírito Santo, Alto Universitário, CEP 29500-000, Alegre (ES). fernandobwef@gmail.com

Recebido para publicação em 29/04/2008 e aceito em 5/05/2009. 
esse tipo de distúrbio, sendo o fogo considerado como um dos fatores determinantes de sua existência (MOREIRA, 1992).

Alterações no regime de fogo do Cerrado, segundo Medeiros e Fiedler (2004), seja pela exclusão total desse elemento ou pelo aumento desordenado na frequência de ocorrência, podem promover mudanças que levam ao comprometimento da manutenção de processos ecológicos e na conservação de espécies em unidades de conservação localizadas neste bioma.

No Distrito Federal, as estatísticas sobre ocorrências de incêndios florestais demonstraram um aumento no número de atendimentos feitos pelo Corpo de Bombeiros nos últimos 10 anos. Partes dessas ocorrências aconteceram nas unidades de conservação, causadas sobretudo por ações antrópicas. Os incendiários e o uso do fogo para limpeza de terrenos próximos às áreas protegidas tem sido as maiores causas dos incêndios florestais (SILVA, 2001).

O baixo nível de cultura em relação às consequências dos incêndios, aliado ao descaso, favorece o desrespeito às leis ambientais. Ribeiro (2003) cita que a educação ambiental na prevenção contra a ocorrência de incêndios florestais é um instrumento que visa à proposição de novos hábitos para a velha prática de uso do fogo, bem como à mudança de consciência do público em geral em favor da conservação dos recursos naturais e da biodiversidade.

Esta pesquisa teve como objetivo analisar aspectos sobre o uso do fogo nas circunvizinhanças urbanas da Estação Ecológica de Águas Emendadas (ESECAE), no Distrito Federal, avaliar as principais ocorrências de incêndios, disponibilidade de equipamentos e ferramentas para a brigada de combate e proporcionar subsídios para diminuição da incidência de incêndios florestais.

\section{MATERIAL E MÉTODOS}

\section{Região de estudo}

A pesquisa foi desenvolvida na Estação Ecológica de Águas Emendadas (ESECAE), localizada em Planaltina, na porção nordeste do Distrito Federal ( $15^{\circ} 32^{\prime}$ a $15^{\circ} 38^{\prime} \mathrm{S}$ e $47^{\circ} 33^{\prime}$ a $\left.47^{\circ} 37^{\prime} \mathrm{W}\right)$.

O clima da Estação Ecológica é classificado, segundo Köppen, como sendo do tipo tropical (Aw) e tropical de altitude (Cwa, $\mathrm{Cwb}$ ), havendo uma estação fria e seca no período de inverno e uma estação quente e chuvosa no período de verão.

Os solos do Distrito Federal, segundo EMBRAPA (1978), pertencem a três classes principais: Latossolo Vermelho Escuro, Latossolo Vermelho Amarelo e Cambissolos, possuindo também uma pequena porcentagem de solos pertencentes às areias Quartzosas e solos Hidromórficos e Lateritas. A altitude varia de 1000 a 1200 metros, com precipitação média anual entre 1200 e $1750 \mathrm{~mm}$. A Figura 1 mostra a Estação Ecológica de Águas Emendadas (ESECAE) e a área de abrangência da pesquisa (3 km no entorno).

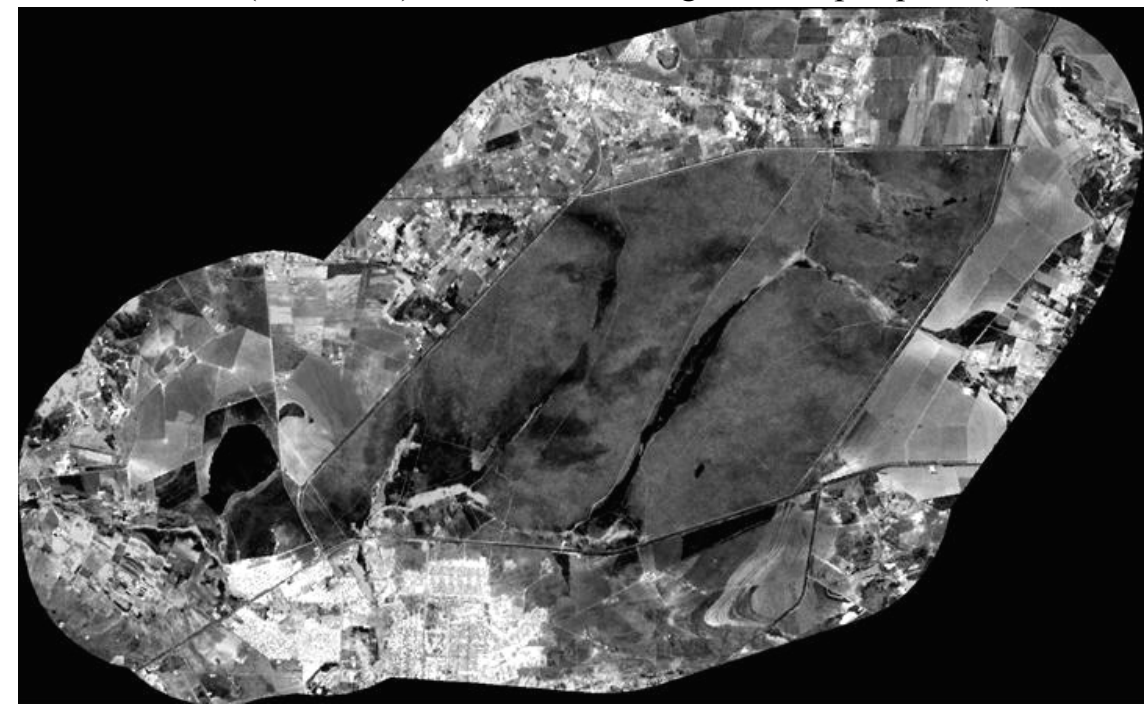

FIGURA 1: Imagem de Satélite da ESECAE e seu entorno (3 km de raio), Planaltina, DF. FIGURE 1: Satellite image of ESECAE and surrounding areas, Planaltina, DF. 


\section{Metodologia da pesquisa social}

A pesquisa realizada foi do tipo quantitativo, sendo adequada para apurar opiniões, atitudes explícitas e a consciência dos entrevistados. As populações foram consideradas homogêneas no que diz respeito à variável a ser amostrada, considerando também que todas as unidades amostrais da população tinham igual chance de participar.

Na realização do levantamento das informações, foram utilizados dois modelos de questionários do tipo estruturado, baseado na metodologia de Gil (1999), com questões abertas e fechadas, aplicados pelo pesquisador à população urbana no entorno da ESECAE, num raio de $3 \mathrm{~km}$ e o outro com os membros da brigada de prevenção e combate aos incêndios florestais, da respectiva unidade de conservação e da guarnição do Corpo de Bombeiros Militar do Distrito Federal do 4ํㅡㄹathão, que também atua na área.

Existem na área urbana aproximadamente 6.500 lotes, com população estimada em 32.500 habitantes. A composição amostral envolveu 494 entrevistas com moradores dessa área mediante sorteio sistemático, sem reposição. Em relação aos membros da brigada e da guarnição, foi realizado um censo com 26 entrevistas.

Para a análise dos dados, foi utilizado o programa estatístico SPSS/PC - (Statistical Package for the Social Sciences), versão 12.0. As frequências obtidas nos resultados referem-se às variáveis do questionário e não aos entrevistados, não possuindo assim, efeito cumulativo. Os entrevistados podem ter respondido ou não, a uma ou mais variáveis, tornando possível assim que determinadas frequências possuam resultados em valores acima de $100 \%$.

\section{Entrevistas com as circunvizinhanças urbanas da ESECAE}

Foram realizadas entrevistas com a população urbana, com aplicação de questionários específicos para melhor caracterização destas, abordando aspectos relacionados à ocorrência dos incêndios florestais, sobre o uso do fogo, noções de prevenção e combate, conhecimento sobre a temática ambiental e qual a importância da unidade de conservação para o meio ambiente.

\section{Entrevistas com a brigada da ESECAE e a guarnição do CBMDF}

Foram aplicados questionários para melhor caracterização da brigada e da guarnição, verificando seu nível de capacitação profissional, tempo de participação, disponibilidade de equipamentos, máquinas e ferramentas para execução das atividades, disponibilidade de equipamentos de proteção individual (EPI'S), principais causas e áreas propensas à ocorrência de incêndios florestais.

\section{RESULTADOS E DISCUSSÃO}

\section{Opinião dos moradores das áreas urbanas vizinhas da ESECAE}

Dos entrevistados na área urbana, a maioria (74\%) residia em imóvel próprio e 18\% moravam de aluguel. De acordo com a Tabela 1, a maioria da população entrevistada ocupava o imóvel há mais de 5 anos $(64 \%)$.

TABELA 1: Tempo de ocupação do imóvel.

TABLE 1: Occupation time of landed property.

\begin{tabular}{lcc}
\hline Tempo de ocupação do imóvel & Frequência Absoluta & Frequência Relativa (\%) \\
\hline Menos de 1 ano & 54 & 11,0 \\
Entre 1 e 4 anos & 124 & 25,0 \\
Entre 5 e 10 anos & 197 & 40,0 \\
Entre 11 e 15 anos & 95 & 19,0 \\
Mais de 15 anos & 24 & 5,0 \\
\hline Total & 494 & 100,0 \\
\hline
\end{tabular}

O uso do fogo como recurso para limpeza do terreno era feito por $34 \%$ dos moradores (Figura 2), e, considerando o tempo de residência no imóvel acima de 5 anos, 22,3\% dos entrevistados utilizavam o fogo (Figura 3). Esta é uma informação relevante, pois incide em área urbana, mostrando possíveis deficiências nas campanhas educativas, particularmente quanto ao trabalho de esclarecimento junto a essa população.

A adoção de palestras e visitas programadas às propriedades do entorno, incluindo assistência técnica específica (queima controlada e opções ao uso do fogo), podem trazer resultados mais expressivos para a 
redução da ocorrência dos incêndios (MEDEIROS e FIEDLER, 2004). Como forma de melhorar a qualidade de vida da população, torna-se recomendável também visitas diretas aos terrenos onde estejam ocorrendo queimas de lixo e orientações em relação ao uso do serviço de coleta, por meio de reuniões com a administração pública local.

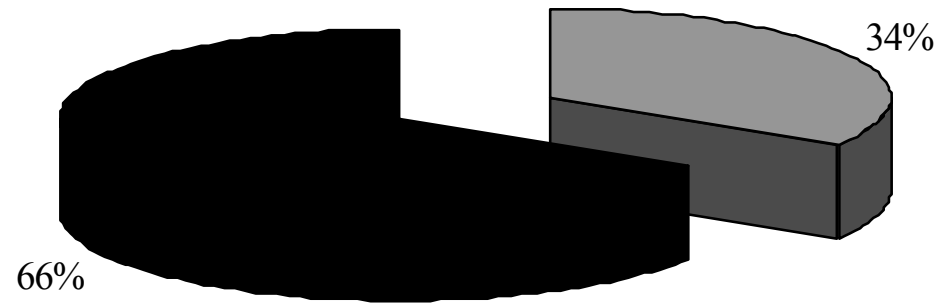

Utiliza fogo na residência Não utiliza fogo na residência

FIGURA 2: Uso do fogo na limpeza dos terrenos.

FIGURE 2: Use of fire as cleanness tool.

A Figura 3 apresenta o cruzamento das informações sobre o tempo de moradia no imóvel e o uso do fogo para limpeza dos terrenos.

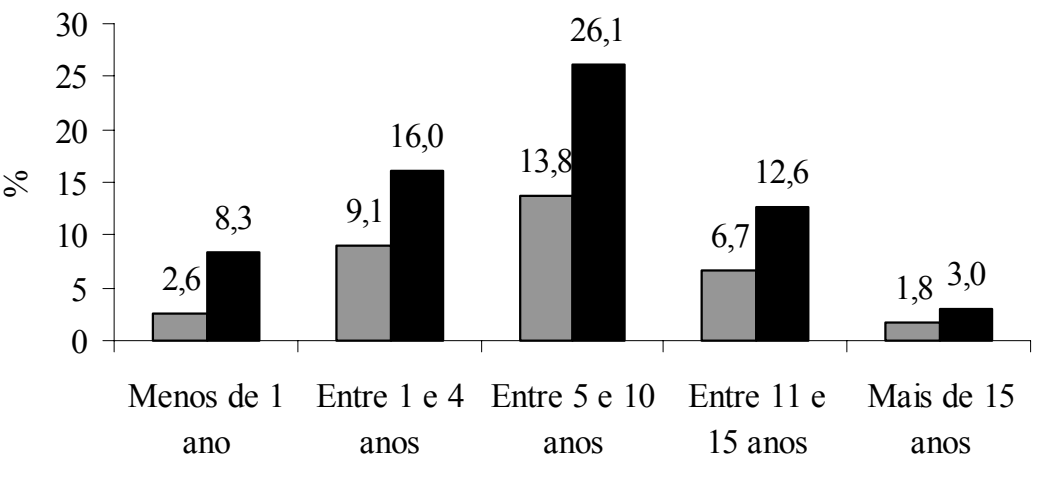

Tempo de ocupação no imóvel

$\square$ Usa fogo na residência $\mathbf{D a ̃ o}$ usa fogo na residência

FIGURA 3: Tempo de moradia x uso do fogo para limpeza dos terrenos.

FIGURE 3: Habitation time $\mathrm{x}$ use of fire as cleanness tool.

Outra informação relevante encontrada foi que $91 \%$ dos entrevistados não receberam nenhuma orientação ou qualquer tipo de treinamento sobre o uso do fogo para limpeza do seu terreno. Entretanto, a ocorrência dos incêndios na ESECAE era do conhecimento de $41 \%$ dos entrevistados (Figura 4).

A educação visando à prevenção a incêndios deve ter participação de entidades oficiais e particulares, visando à conscientização da população sobre técnicas de prevenção e combate. Pequenos proprietários geralmente não possuem condições para o desenvolvimento de trabalhos isolados de proteção, em decorrência das limitações financeiras. Associações particulares, englobando organizações de poderio econômico, pequenos proprietários e entidades oficiais, reunindo-se em ação cooperativa, têm condições de realizar melhor essa tarefa, durante a prevenção, localização e extinção dos incêndios em seu início (MEDEIROS, 2002).

A utilização de queimadas em mutirão e/ou o aviso aos vizinhos são práticas simples que têm sido eficientes para a redução de incêndios florestais em comunidades rurais na Amazônia (NEPSTAD et al., 1999). Práticas similares também podem ser empregadas na região do Cerrado com custos reduzidos de treinamento. A Figura 4 mostra o conhecimento da população urbana sobre a ocorrência de incêndios florestais na Estação Ecológica de Águas Emendadas. 


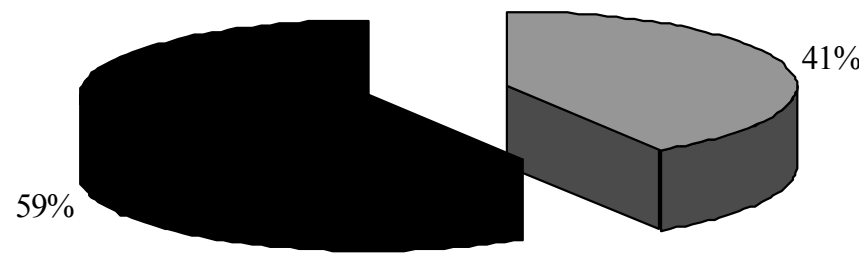

$\square \operatorname{Sim} \square$ Não

FIGURA 4: Conhecimento da população urbana sobre a ocorrência de incêndios na ESECAE.

FIGURE 4: People knowledge about fires at ESECAE.

Dos moradores entrevistados, quase $84 \%$ preocupavam-se com a ocorrência de incêndios florestais na ESECAE e acreditavam que a ocorrência dos mesmos afetava suas atividades econômicas ou a qualidade de vida (Figura 5).

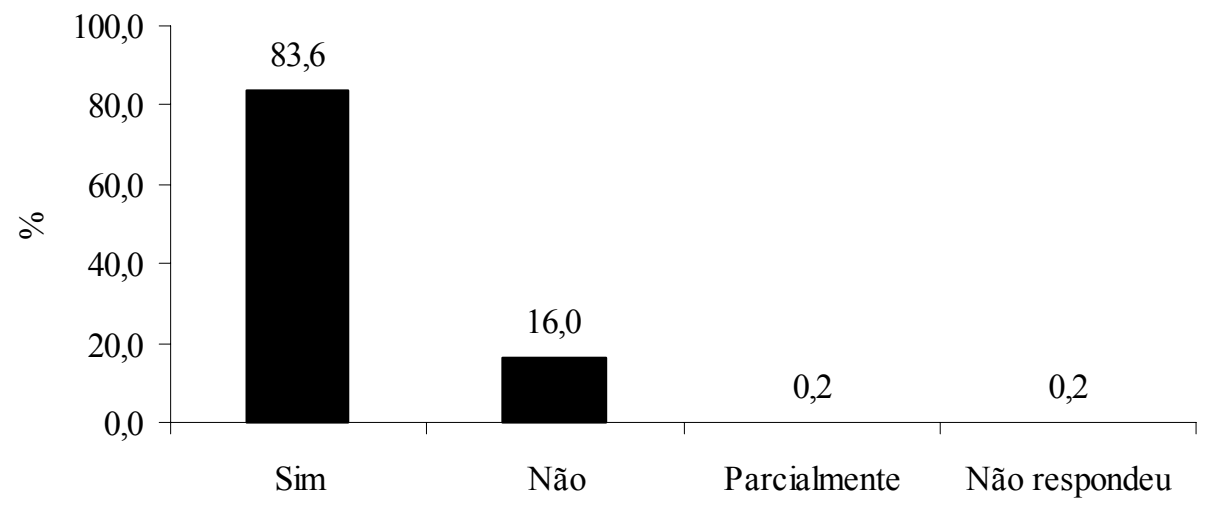

Preocupação do morador com a ocorrência de incêndios florestais

FIGURA 5: Preocupação com a ocorrência de incêndios florestais.

FIGURE 5: Worries about forest fires.

Na Figura 6, observa-se que $88 \%$ dos moradores urbanos nunca participaram de nenhum tipo de atividade relacionada à prevenção ou ao combate aos incêndios florestais. Em uma unidade de conservação circundada por zonas urbanas, este é um dado que expõe a falta de percepção e interação do público externo com a ESECAE.

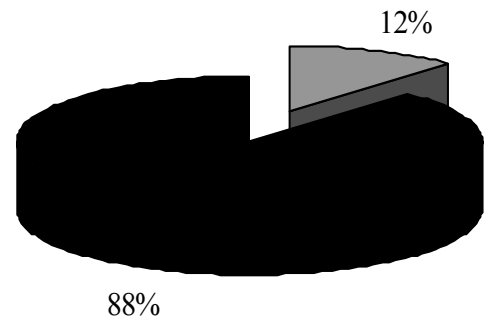

$\square$ Participa da atividade de combate aos incêndios florestais

Não participa da atividade de combate aos incêndios florestais

FIGURA 6: Participação do morador em atividades de prevenção ou combate aos incêndios florestais. FIGURE 6: Residence partnership in activities of forest fire prevention or combat. 
No cruzamento entre o tempo de moradia no imóvel e o treinamento recebido pelo morador sobre o uso do fogo (Figura 7), observa-se que o aumento no tempo de ocupação é diretamente proporcional ao aumento dos moradores que não receberam nenhum tipo de treinamento até aos 10 anos de ocupação do imóvel. A maior discrepância ocorreu do quinto ao décimo ano, quando a diferença das pessoas que não receberam instruções foi cerca de 13 vezes superior àquelas que receberam algum tipo de orientação.

Esse resultado evidencia o desconhecimento por parte da população quanto ao uso do fogo e os riscos que podem causar ao meio ambiente, reforçando assim, a necessidade de serem intensificadas as campanhas educativas junto às comunidades vizinhas.

As atividades de educação ambiental devem ser fundamentadas principalmente em palestras e visitas programadas ao entorno da unidade de conservação, onde esse tipo de investimento, geralmente, é bastante reduzido em relação aos custos das operações de combate aos incêndios.

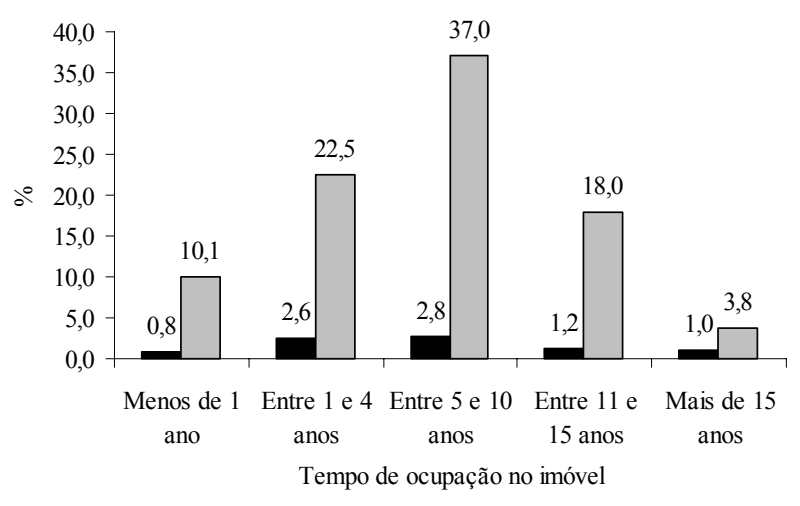

Recebeu treinamento $\square$ Não recebeu treinamento

FIGURA 7: Treinamento recebido pelo morador sobre uso do fogo $\mathrm{x}$ tempo de ocupação do imóvel.

FIGURE 7: Experience with fire use $\mathrm{x}$ occupation time of landed property.

Verificou-se ainda, que a maior parcela da população (72\%) não tinha conhecimento sobre qualquer programa relacionado à temática ambiental por parte dos funcionários da Estação Ecológica de Águas Emendadas, no que se referem às campanhas educativas, programas de prevenção e combate aos incêndios florestais ou técnicas de queimada controlada. Entre os moradores que reconheceram as atividades desenvolvidas pela ESECAE junto às comunidades, tiveram maior importância as campanhas educativas $(23,7 \%)$ e os trabalhos de fiscalização (11,3\%), como pode ser visto na Figura 8. A ausência de campanhas educativas no entorno de unidades de conservação tem sido uma das principais causas de ocorrência de incêndios florestais nos seus interiores (MEDEIROS e FIEDLER, 2004; FIEDLER et al., 2006a).

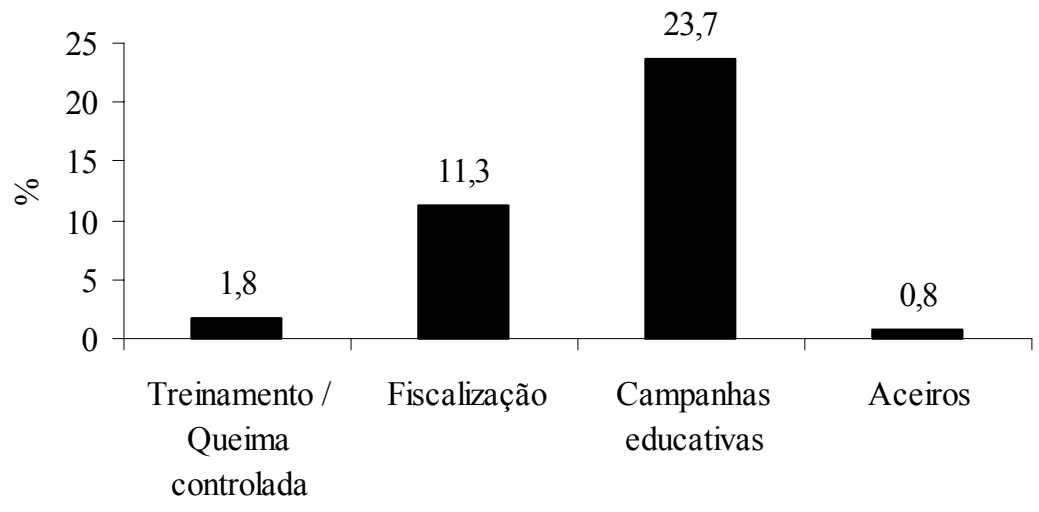

Principais programas desenvolvidos

FIGURA 8: Principais programas desenvolvidos em prevenção e combate aos incêndios florestais.

FIGURE 8: Main programs developed for forest fires prevention and combat.

As atividades preventivas para controle do fogo têm sido mais eficientes quando as comunidades são orientadas em um trabalho local, com contatos diretos entre técnicos e produtores. Na Amazônia, algumas 
comunidades de pequenos produtores têm sido orientadas localmente dessa forma, com resultados bastante positivos (NEPSTAD et al., 1999).

As principais causas de ocorrência, em ordem decrescente, de incêndios florestais em Águas Emendadas, como se pode observar na Figura 9, são: incendiários $(64,4 \%)$, queima de pastagens $(47,8 \%)$ e fagulhas de veículos automotores e queima de lixo (plásticos, papéis, filtros de cigarro ainda acesos) nas margens de rodovias e estradas vicinais (38,9\%). Tais padrões de causas são muito comuns em unidades de conservação do Cerrado (MEDEIROS e FIEDLER, 2004; FIEDLER et al., 2006a; LARA et al., 2007). Foi verificado ainda que causas naturais e diversas foram pouco citadas pelos entrevistados e somente $3 \%$ destes não responderam a esta questão. Alguns estudos em unidades de conservação desse bioma verificaram frequência elevada de incêndios causados por raios, fato não observado nesta pesquisa.

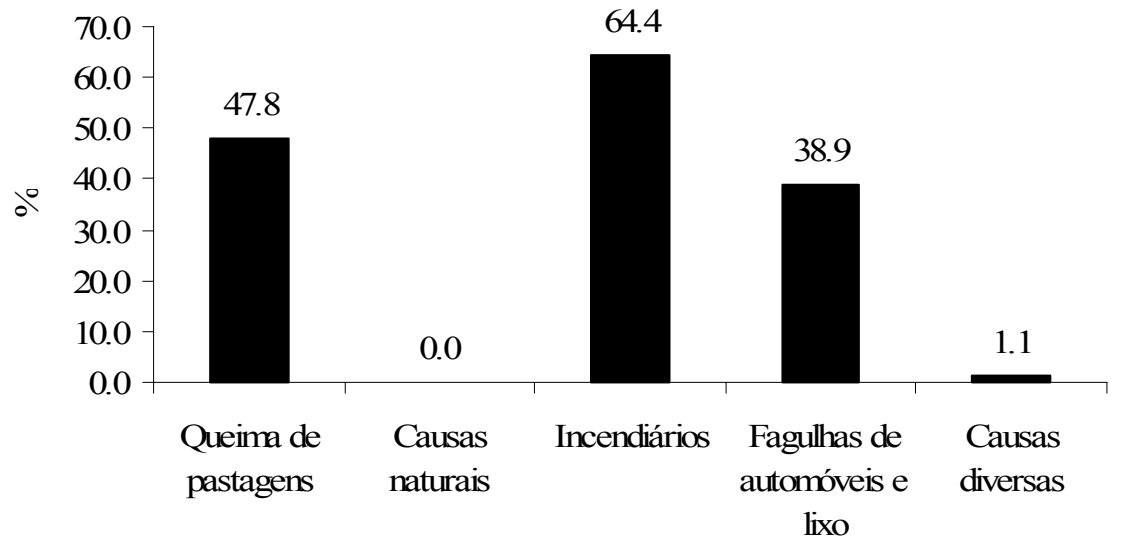

FIGURA 9: Principais causas de ocorrência de incêndios florestais conforme população urbana. FIGURE 9: Main causes of forest fires occurrences according to local population.

Os locais de maior ocorrência de incêndios identificados pelos entrevistados (Figura 10) foram às margens de rodovias e estradas vicinais $(33,4 \%)$, as propriedades rurais do entorno $(10,9 \%)$, os condomínios urbanos (10,5\%) e o interior da Estação Ecológica de Águas Emendadas (9,1\%).

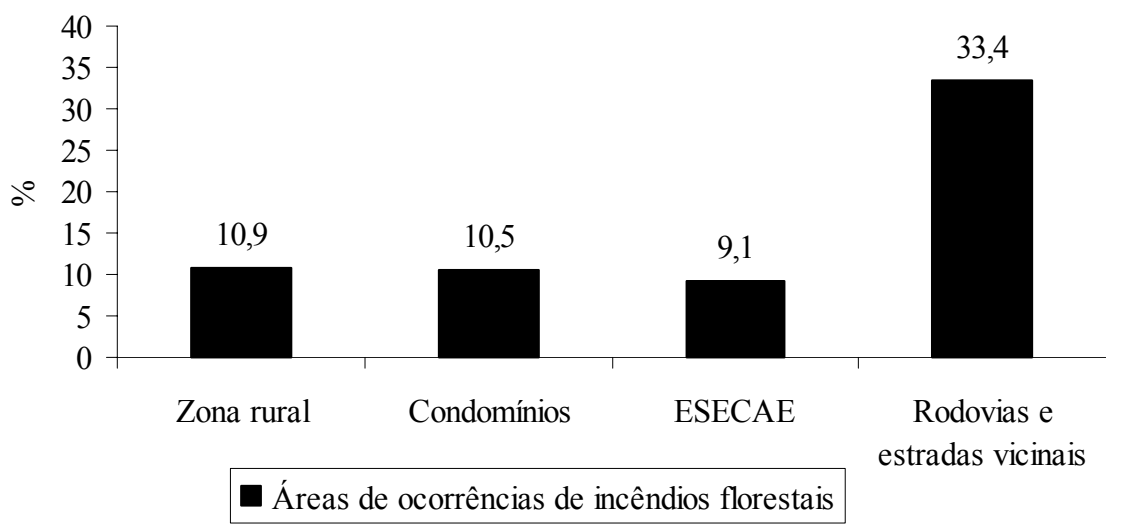

FIGURA 10: Áreas de ocorrência de incêndios florestais (população urbana).

FIGURE 10: Occurrences forest fires areas (urban population).

Quanto a outros comentários, o tópico mais abordado por aproximadamente metade dos entrevistados foi a necessidade de infra-estrutura como águas pluviais, asfalto, saneamento básico, seguido de aspectos relacionados ao meio ambiente, educação, emprego, segurança e lazer.

\section{Opinião dos membros da brigada e da guarnição}

Os resultados das entrevistas aplicadas aos brigadistas mostraram que existe um elevado percentual de trabalhadores com tempo de atuação entre 1 e 5 anos $(42,3 \%)$ e acima de 10 anos $(38,5 \%)$, conforme mostrado na Figura 11. Do total dos membros da brigada da unidade de conservação, $23,1 \%$ não receberam nenhum treinamento para a atividade. Ressalta-se que a ausência de capacitação profissional pode implicar 
em avaliações indevidas dos riscos envolvidos nas atividades de prevenção e pré-supressão, uso inadequado dos equipamentos, ferramentas e máquinas, prejudicando assim a realização dos trabalhos nos momentos críticos.

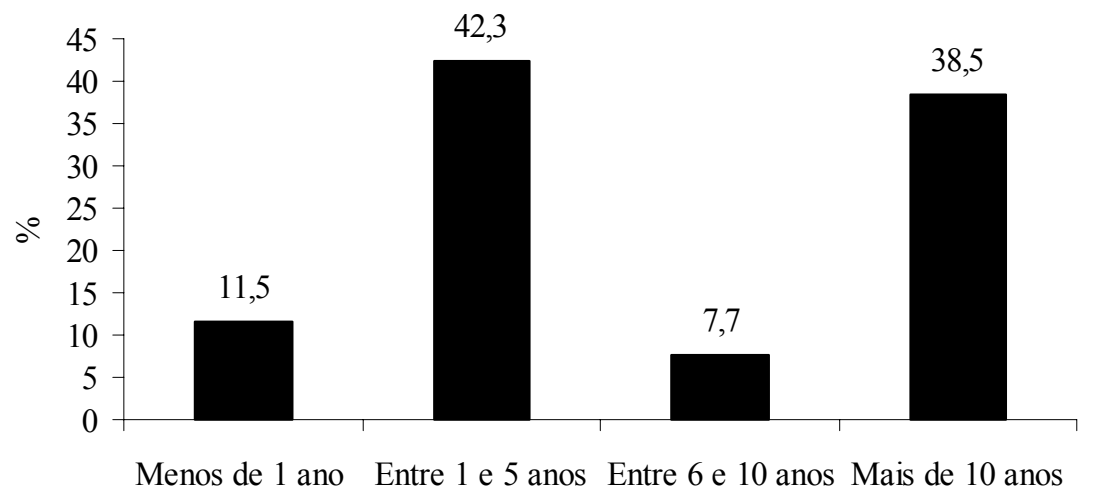

Tempo de atuação

FIGURA 11: Tempo de atuação na brigada de combate aos incêndios florestais.

FIGURE 11: Performance time as combatant in forest fires.

Pela Tabela 2, observa-se que mais de $92 \%$ dos brigadistas acharam insuficiente a quantidade de equipamentos de proteção individual (EPI's) para atendê-los. O combate a incêndios florestais é uma atividade notoriamente desgastante. Aliado a todo o desgaste físico, se as condições de trabalho forem precárias, haverá comprometimento dos níveis de saúde, segurança, bem-estar e satisfação do trabalhador. Esse comprometimento poderá levar a altos índices de acidentes do trabalho, surgimento de doenças relacionadas ao trabalho, insatisfação, baixa qualidade e produtividade dos serviços (FIEDLER et al., 2006b).

A carência e a inadequação de EPI's também parecem ser comuns a muitas brigadas de combate a incêndios florestais no Brasil, sendo esse item um dos principais responsáveis pelo baixo grau de eficiência das atividades de combate (MEDEIROS e FIEDLER, 2004; MEDEIROS 2002).

Os militares da guarnição do CBMDF possuíam fardamento completo, não sendo notificado reclamações nesse item. Quanto à disponibilidade de máquinas, equipamentos e ferramentas para a execução das atividades de prevenção e combate, cerca de $65 \%$ dos bombeiros entrevistados a consideraram satisfatória. A disponibilidade de equipamentos específicos para as atividades de combate aos incêndios florestais tem sido um dos pontos fundamentais para a melhoria da eficiência da supressão de incêndios em unidades de conservação (PEREIRA et al., 2004).

TABELA 2: Equipamentos de proteção individual, máquinas, equipamentos e ferramentas disponíveis. TABLE 2: Equipment availability for individual protection and machines, equipments and tools.

\begin{tabular}{l|c|c|c|c}
\hline \multirow{2}{*}{} & \multicolumn{2}{|c|}{$\begin{array}{c}\text { Disponibilidade de equipamentos de proteção } \\
\text { individual (EPI's) }\end{array}$} & $\begin{array}{c}\text { Disponibilidade de máquinas, equipamentos e } \\
\text { ferramentas }\end{array}$ \\
\cline { 2 - 5 } & Freqüência absoluta & Freqüência relativa (\%) & Freqüência absoluta & Freqüência relativa (\%) \\
\hline Sim & 2 & 7,7 & 10 & 38,5 \\
Não & 19 & 73,1 & 9 & 34,6 \\
Parcialmente & 5 & 19,2 & 7 & 26,9 \\
Total & 26 & 100 & 26 & 100 \\
\hline
\end{tabular}

Referente aos trabalhos de combate aos incêndios florestais, foi observado que a brigada tem atuado em conjunto com outras brigadas (Tabela 3). Isso é relevante, pois há oportunidade de trocas de experiências, possibilidade de conhecer outras áreas e profissionais e técnicas diferenciadas de combate ao fogo. A maior atuação conjunta foi verificada com a brigada da Reserva Ecológica do IBGE, com 88,5\%, seguida pela brigada do Jardim Botânico de Brasília (73,1\%). 
TABELA 3: Atuação conjunta com outras brigadas de unidades de conservação do Distrito Federal.

TABLE 3: United action with another combat in conservation units, Distrito Federal.

\begin{tabular}{lccc}
\hline Locais que possuem brigadas no DF & Frequência absoluta & Frequência relativa (\%) \\
\hline Reserva Ecológica do IBGE & 23 & 88,5 \\
Parque Nacional de Brasília & 15 & 57,7 \\
Fazenda Água Limpa da UnB & 4 & 15,4 \\
Jardim Botânico & 19 & 73,1 \\
Brigadas Voluntárias & 8 & 30,8 \\
\hline
\end{tabular}

Para $84,6 \%$ dos que atuavam diretamente no combate aos incêndios, a atividade de maior importância foi construção e manutenção de aceiros na unidade de conservação, seguido das atividades de fiscalização e vigilância (76,9\%), campanhas educativas $(30,8 \%)$ e capacitação e treinamento $(23,1 \%)$. Entretanto, segundo os combatentes já capacitados (Tabela 4), as atividades de aceiramento (57,7\%) e disponibilidade de máquinas, equipamentos e ferramentas $(23,1 \%)$ eram as que apresentavam as maiores necessidades de melhoria.

Em algumas unidades de conservação do Cerrado, como os Parques Nacionais de Emas, Chapada dos Veadeiros, Sete Cidades e Brasília, a execução de aceiros externos (no entorno) e internos tem diminuído de modo significativo a frequência e a extensão das áreas atingidas, sendo fundamentais para a quebra dos ciclos de grandes incêndios que ocorriam com intervalos de três/quatro anos (MEDEIROS e FIEDLER, 2004).

TABELA 4: Capacitação do brigadista x necessidade de melhoria no sistema de prevenção e combate.

TABLE 4: Combatant qualify $\mathrm{x}$ improvement needs on prevention and combat system.

\begin{tabular}{l|c|c|c|c|c|c}
\hline $\begin{array}{l}\text { Onde existe necessidade de } \\
\text { melhoria no sistema de } \\
\text { prevenção e combate? }\end{array}$ & Aceiros & $\begin{array}{l}\text { Campanhas } \\
\text { educativas }\end{array}$ & Fiscalização & Treinamentos & $\begin{array}{c}\text { Equip./ } \\
\text { Ferramentas }\end{array}$ & Total \\
\hline $\begin{array}{l}\text { Brigadistas capacitados } \\
\text { Brigadistas não capacitados }\end{array}$ & 12 & 1 & 2 & 1 & 4 & 20 \\
\hline Total & 15 & 1 & 2 & 2 & 6 & 6 \\
\hline
\end{tabular}

Entre as prováveis causas dos incêndios florestais (Figura 12), todos os brigadistas consideraram as ações de incendiários como mais relevantes. Este é um problema que atinge sobretudo unidades de conservação circundadas por zonas urbanas e também aquelas circundadas por áreas rurais, mas com carência de interações positivas com o entorno, como campanhas educativas (MEDEIROS e FIEDLER, 2004).

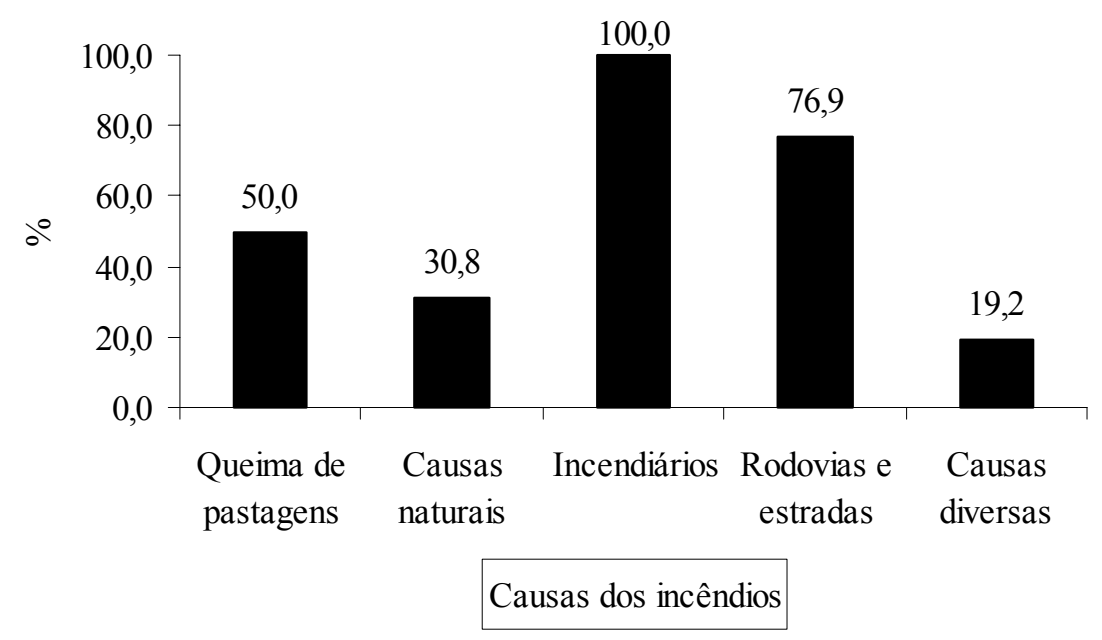

FIGURA 12: Opinião dos brigadistas sobre as principais causas de incêndios florestais na ESECAE. FIGURE 12: Combatants' opinions about main forest fires causes at ESECAE. 
Para aproximadamente $77 \%$ dos brigadistas, dever-se-ia dar importância aos incêndios com origem às margens de estradas vicinais e rodovias (causados por veículos, fumantes e outros). Segundo $50 \%$ dos brigadistas, cuidados deveriam ser tomados também ao uso do fogo na limpeza dos terrenos e para fins agropastoris, como a renovação de pastagens e preparo do solo para plantio na zona rural, o que mostrou uma boa percepção do grupo sobre as principais causas de ocorrência de incêndios, considerando esse padrão similar em outras unidades de conservação do Cerrado (MEDEIROS e FIEDLER, 2004; FIEDLER et al., 2006a; LARA et al., 2007).

A coordenação da brigada foi avaliada satisfatoriamente pelos brigadistas, e $80 \%$ afirmaram haver necessidade de aumento do número de combatentes (acréscimo entre cinco a oito pessoas). Pouco mais de $40 \%$ dos brigadistas optaram por fazer algum comentário, e destes, $80 \%$ abordaram temas relacionados aos equipamentos, máquinas e ferramentas para atividades de prevenção e combate ao fogo; e $12 \%$ sobre a necessidade de regulamentação do cargo ou função.

A Tabela 5 apresenta o cruzamento entre a capacitação da brigada e a disponibilidade de máquinas, equipamentos e ferramentas para o desenvolvimento dos trabalhos. Destes, 65,4\% dos entrevistados consideraram aceitáveis os equipamentos e ferramentas das brigadas.

TABELA 5: Capacitação do brigadista x suficiência em máquinas, equipamentos e ferramentas.

TABLE 5: Combatant qualify $\mathrm{x}$ machines, equipments and tools adequacy.

\begin{tabular}{l|c|c|c|c}
\hline $\begin{array}{l}\text { Os equipamentos e ferramentas são suficientes no trabalho } \\
\text { de prevenção e combate aos incêndios florestais? }\end{array}$ & Sim & Não & Parcialmente & Total \\
\hline Brigadistas capacitados & 5 & 8 & 7 & 20 \\
Brigadistas não capacitados & 5 & 1 & 0 & 6 \\
\hline Total & 10 & 9 & 7 & 26 \\
\hline
\end{tabular}

No cruzamento das informações obtidas entre o nível de capacitação dos brigadistas e os trabalhos de prevenção desenvolvidos (Tabela 6), foi observado que não ocorreu alteração significativa na avaliação dos principais trabalhos em função do nível de capacitação, pois ambos consideraram o aceiramento como atividade mais importante.

TABELA 6: Capacitação do brigadista $\mathrm{x}$ trabalhos de prevenção desenvolvidos pela brigada.

TABLE 6: Combatant qualify x prevention efforts developed by combat.

\begin{tabular}{l|c|c|c|c|c}
\hline $\begin{array}{l}\text { Quais são os principais trabalhos } \\
\text { de prevenção (pré-supressão) } \\
\text { desenvolvidos pela brigada? }\end{array}$ & Aceiros & $\begin{array}{c}\text { Campanhas } \\
\text { educativas }\end{array}$ & Fiscalização & Treinamentos & Total \\
\hline Brigadistas capacitados & 14 & 2 & 3 & 1 & 20 \\
Brigadistas não capacitados & 6 & 0 & 0 & 0 & 6 \\
\hline Total & 20 & 2 & 3 & 1 & 26 \\
\hline
\end{tabular}

Em outra parte da entrevista, notou-se que a ação de incendiários foi citada como a principal causa de incêndios florestais na avaliação dos brigadistas capacitados. Para os não capacitados, a principal causa foi o incêndio originado em margens de estradas vicinais e rodovias provocados por veículos, fumantes, etc., conforme analisado na Tabela 7.

TABELA 7: Capacitação do brigadista x principais causas de incêndios florestais.

TABLE 7: Combatant qualify x main forest fires causes.

\begin{tabular}{l|c|c|c|c}
\hline $\begin{array}{l}\text { Quais são as principais causas de incêndios } \\
\text { florestais em Águas Emendadas? }\end{array}$ & $\begin{array}{c}\text { Queima de } \\
\text { pastagens }\end{array}$ & Incendiários & $\begin{array}{c}\text { Rodovias e estradas } \\
\text { vicinais }\end{array}$ & Total \\
\hline Brigadistas capacitados & 3 & 14 & 3 & 20 \\
Brigadistas não capacitados & 1 & 2 & 3 & 6 \\
\hline Total & 4 & 16 & 6 & 26 \\
\hline
\end{tabular}

O entrelaçamento das informações entre os locais de maior incidência de incêndios florestais e capacitação do brigadista (Tabela 8), mostrou que há coincidência entre os dois grupos, sendo aqueles que têm origem em rodovias e estradas vicinais. 
TABELA 8: Capacitação do brigadista $\mathrm{x}$ locais de maior incidência de incêndios florestais.

TABLE 8: Combatant qualify $\mathrm{x}$ most locals forest fires incidence.

\begin{tabular}{l|c|c|c|c|c}
\hline $\begin{array}{l}\text { Local de maior incidência de } \\
\text { incêndios florestais }\end{array}$ & $\begin{array}{c}\text { Região do } \\
\text { Monteiro }\end{array}$ & $\begin{array}{c}\text { Região da } \\
\text { Lagoa Bonita }\end{array}$ & $\begin{array}{c}\text { Rodovias e } \\
\text { estradas vicinais }\end{array}$ & $\begin{array}{c}\text { Condomínios } \\
\text { urbanos vizinhos }\end{array}$ & Total \\
\hline Brigadistas capacitados & 5 & 1 & 12 & 2 & 20 \\
Brigadistas não capacitados & 0 & 0 & 5 & 1 & 6 \\
\hline Total & 5 & 1 & 17 & 3 & 26 \\
\hline
\end{tabular}

Disponibilidade de máquinas, equipamentos e ferramentas para a brigada

A brigada da ESECAE tinha, na época da coleta de dados, uma boa disponibilidade de máquinas, equipamentos e ferramentas para combate aos incêndios florestais, com ônibus, veículo utilitário e caminhonete para transporte de pessoal e material, caminhão pipa, trator de pneus, tanque pipa de engate em trator, motosserra, aparelho de GPS, binóculos, torres de observação, bússolas e mapas, bombas costais, abafadores, enxadas e pás para todos os brigadistas, além de lanternas profissionais para o trabalho noturno. Verificou-se que em função do número de brigadistas em atuação, existe disponibilidade de equipamentos, máquinas e ferramentas para a execução das atividades de prevenção e combate.

O sistema de detecção deve ter como padrão características que incluam a rápida localização dos focos e a precisão dessa localização. Além disso, deve abranger os períodos diurno e noturno, e a localização dos focos idealmente deve ocorrer sobre quaisquer condições de visibilidade.

Para que um combate seja eficaz, é necessário, acima de tudo, que os brigadistas estejam bem treinados, equipados e que as condições de trabalho sejam adequadas. Deve-se ter também a implementação de mecanismos para realização de perícia nos incêndios florestais, possibilitando a identificação do local ou locais de origem e as prováveis causas, e que no caso de incêndios criminosos os culpados sejam responsabilizados judicialmente (MEDEIROS e FIEDLER 2004; PEREIRA et. al., 2004).

Para melhorar a segurança e rapidez nos trabalhos de prevenção e combate, foi recomendada a aquisição de um sistema de comunicação para os veículos e frentes de combate (portáteis), um novo caminhão pipa (capacidade mínima de 12.000 litros); uma caminhonete com tração 4X4; um trator de pneus com implementos; motocicletas e aparelhos de GPS para georreferenciamento das ocorrências.

\section{CONCLUSÕES}

Com base nos resultados obtidos na pesquisa, as seguintes conclusões podem ser apresentadas:

Os condomínios urbanos vizinhos e margens de rodovias e estradas vicinais que circundam a ESECAE são áreas muito propensas a ocorrências de incêndios florestais.

Grande parte dos incêndios florestais foi provocada por incendiários e tem origem, na maioria das vezes, às margens de rodovias e estradas vicinais próximas da ESECAE.

Existe insuficiência de equipamentos de proteção individual para os brigadistas e a ESECAE não dispõe de máquinas para manutenção das estradas e aceiros.

O sistema de treinamento de brigadistas mostrou-se insuficiente e há necessidade que todos os membros da brigada sejam capacitados e participem de programas de condicionamento físico.

A atuação da educação ambiental no entorno da ESECAE é insuficiente e deve ser melhorada em função da elevada demanda na área urbana e problemas ambientais ainda recorrentes.

Os brigadistas mostraram-se satisfeitos no trabalho, reconhecem as dificuldades e limitações e sugerem melhorias como a manutenção de aceiros e cuidados com equipamentos e maquinário.

\section{REFERÊNCIAS BIBLIOGRÁFICAS}

EMBRAPA. Empresa Brasileira de Pesquisa Agropecuária. Serviço Nacional de Levantamento e Conservação de Solos. Levantamento de reconhecimento dos solos do Distrito Federal. Rio de Janeiro: Embrapa-SNLCS, 1978. 455 p. (Boletim Técnico, 53).

FIEDLER, N. C.; MERLO, D. A.; MEDEIROS, M. B. Ocorrência de incêndios florestais no Parque Nacional da Chapada dos Veadeiros, Goiás. Ciência Florestal, Santa Maria, v. 16, n. 2, p. 153-161, jul./dez. 2006a.

FIEDLER, N. C.; RODRIGUES, T. O.; MEDEIROS, M. B. de. Avaliação das condições de trabalho, treinamento, 
saúde e segurança de brigadistas de combate a incêndios florestais em unidades de conservação do Distrito Federal estudo de caso. Revista Árvore, Viçosa, v. 30, n. 1, p. 55-63, jan./fev. 2006 b.

GIL, A. C. Métodos e técnicas de pesquisa social. 5. ed. São Paulo. ATLAS, 1999. 206 p.

LARA, D. X.; FIEDLER, N. C.; MEDEIROS, M. B. Uso do fogo em propriedades rurais do Cerrado em Cavalcante, GO. Ciência Florestal, Santa Maria, v. 17, n. 1, p. 9-15, jan./jun. 2007.

MEDEIROS, M. B. Manejo do Fogo em unidades de conservação do Cerrado. Boletim do Herbário Ezechias Paulo Heringer, Brasília, n.10, p.76-89, 2002.

MEDEIROS, M. B.; FIEDLER, N. C. Incêndios florestais no Parque nacional da Serra da Canastra: desafios para a conservação da biodiversidade. Ciência Florestal, Santa Maria, v. 14, n. 2, p. 157-168. jul./dez. 2004.

MOREIRA, A. G. Fire Protection and Vegetation Dynamics in the Brazilian Cerrado. 1992. 201p. Thesis (Ph.D.) Harvard University, Cambridge, Massachusetts.

NEPSTAD, D. C.; MOREIRA, A. G.; ALENCAR, A. A. Flames in the Forest: origins, impacts and alternatives to amazonian fires. Brasília: The Pilot Program to Conserv the Brazilian Rain Forest, $1999.90 \mathrm{p}$.

PEREIRA, C. A.; FIEDLER, N. C.; MEDEIROS, M. B. Análise de ações de prevenção e combate aos incêndios florestais em unidades de conservação do Cerrado. Revista Floresta, Curitiba, v. 34, n. 2, p. 95-100, abr./jun. 2004.

RIBEIRO, G. A. Planejamento e proteção contra os incêndios florestais. In: FÓRUM DO PLANO DE PREVENÇÃO E COMBATE AOS INCÊNDIOS FLORESTAIS DO DISTRITO FEDERAL, 6., 2003, Brasília. Anais... Brasília: 2003. p. 111-126.

SILVA, J. C. Diagnóstico das áreas de maior incidência de incêndios florestais em unidades de conservação pertencentes a APA do Gama Cabeça de Veado, Brasília-DF. 2001. 59 f. Dissertação (Mestrado em Engenharia Florstal) - Universidade de Brasília. 